\title{
Efeito de probiótico na infecção e excreção fecal de Salmonella em suínos
}

\author{
Effect of probiotic on the Salmonella infection and fecal excretion in pigs \\ Mariana Gomes Nogueira' Juliana Cafruni Calveyra ${ }^{I}$ Jalusa Deon KichII \\ Arlei ColdebellaII Nelson Mores ${ }^{\mathrm{II}}$ Marisa Ribeiro de Itapema Cardoso ${ }^{\mathrm{III}}$
}

\section{RESUMO}

A transmissão de Salmonella na cadeia produtiva de suínos é um problema de difícil controle. O objetivo do estudo foi avaliar o efeito da administração oral de probiótico sobre a ocorrência de infecção e excreção fecal de Salmonella em suínos em fase de crescimento. Os tratamentos consistiram de ração basal sem aditivos (controle) ou adicionada de probiótico $\left(10^{7} u f c g^{-1}\right.$ de células viáveis dos gêneros Bifidobacterium, Enterococcus, Lactobacillus $e$ Saccharomyces). Foram alocados seis leitões de 50 dias em cada tratamento, com duas repetições por tratamento. Todos os animais foram inoculados com Salmonella Typhimurium $\left(10^{6} u \mathrm{fc} \mathrm{mL}^{-1}\right)$ após 14 dias do alojamento. Semanalmente, foram coletadas amostras de sangue e fezes e no dia 35 pósinoculação os animais foram sacrificados e necropsiados. Os animais de ambos os tratamentos foram infectados por Salmonella e soroconverteram. Não houve diferença $(P>0,05)$ entre os grupos nas médias de Salmonella, Enterococcus, Lactobacillus e coliformes totais nas fezes, porém a administração de probiótico resultou em menor frequência de isolamento de Salmonella a partir de fígado $(P=0,04)$, linfonodos mesentéricos $(P=0,04)$, pulmão $(P=0,03)$ e baço $(P=0,01)$. Conclui-se que os microrganismos probióticos testados não foram capazes de impedir a infecção ou a excreção fecal de Salmonella em suínos de crescimento, mas diminuíram o número de portadores em linfonodos mesentéricos.

Palavras-chaves: controle biológico, suínos em crescimento, soroconversão, portadores, linfonodos mesentéricos.

\section{ABSTRACT}

Control of Salmonella transmission has been a challenge for the pork production companies. The aim of this study was to evaluate the effect of oral administration of probiotics on the occurrence of infection and fecal excretion of Salmonella in growers. The treatments consisted of basal diet without additives (control) or added of probiotic $\left(10^{7} \mathrm{cfu} \mathrm{g}^{-1}\right.$ of viable cells of the genera Bifidobacterium, Enterococcus, Lactobacillus and Saccharomyces). Six 50 days-old pigs were allocated into each treatment, with two replicates per treatment. All animals were inoculated with Salmonella Typhimurium $\left(10^{6} \mathrm{cfu} \mathrm{mL}^{-1}\right)$ after 14 days of housing. Afterwards, blood and feces samples were taken weekly and on day 35 post-inoculation the animals were euthanized and necropsied. The animals in both treatment groups were infected by Salmonella and seroconverted. There was no difference $(P>0.05)$ between groups in mean counts of Salmonella, Enterococcus, Lactobacillus and coliforms in the feces samples, but the probiotic administration resulted in a lower frequency of isolation of Salmonella from liver $(P=0.04)$, mesenteric lymph nodes $(P=0.04)$, lung $(P=0.03)$ and spleen $(P=0.01)$. It was concluded that the probiotic microorganisms tested in this study were not able to protect against the infection or to decrease the fecal excretion of Salmonella in growing pigs, but were able to decrease the number of carriers in the mesenteric lymph nodes.

Key words: biological control, growers, seroconvertion, mesenteric lymph nodes, carriers.

\section{INTRODUÇÃO}

Os suínos podem ser portadores e excretar uma variedade de sorovares de Salmonella sem apresentar sinais clínicos, transmitindo a bactéria ao longo da cadeia de produção e constituindo fonte de

'Programa de Pós-graduação em Ciências Veterinárias, Faculdade de Veterinária, Universidade Federal do Rio Grande do Sul (UFRGS), Porto Alegre, RS, Brasil.

"Embrapa Suínos e Aves, Concórdia, SC, Brasil.

IIIDepartamento de Medicina Veterinária Preventiva, Faculdade de Veterinária, UFRGS, Av. Bento Gonçalves 9090, 90540-000, Porto Alegre, RS, Brasil. E-mail: mcardoso@ufrgs.br. Autor para correspondência. 
contaminação para carcaças ao abate (BOYEN et al., 2008). Por essa razão, programas de controle devem propor alternativas integradas, contemplando boas práticas nas fábricas de ração, nas granjas e nos matadouros. O programa pode associar estratégias adicionais de controle, como o uso de vacinas, prebióticos e probióticos (LETELLIER et al., 2001), porém o uso de antimicrobianos é pouco eficiente na eliminação do estado de portador nos suíno portadores (FEDORKACRAY et al., 1999).

Probióticos são aditivos dietéticos constituídos por bactérias vivas que colonizam o intestino e podem ocasionar a exclusão competitiva dos patógenos (CALLAWAY et al., 2008). Vários microrganismos são incluídos em formulações probióticas, destacando-se os gêneros Lactobacillus, Bifidobacterium e Enterococcus. O efeito favorável desses aditivos para o controle de patógenos entéricos tem sido demonstrado em suínos (DE ANGELIS et al., 2007; WALSH et al., 2008).

Estudo conduzido no sul do Brasil demonstrou que o número de suínos portadores de Salmonella ao abate é elevado (SCHWARZ et al., 2009). $\mathrm{O}$ aumento do número de animais infectados tem sido detectado nas fases de crescimento e terminação (KICH et al., 2007), justificando a aplicação de medidas de controle nessas fases. Entre as intervenções possíveis, o fornecimento, via ração, de aditivos que permitam a diminuição do número de suínos infectados ou que excretem Salmonella nas fezes, pode contribuir para alcançar um menor número de animais portadores ao abate. Uma vez que os probióticos têm sido utilizados com sucesso no controle de doenças entéricas, o objetivo deste estudo foi avaliar o efeito da administração oral de probiótico sobre a infecção por Salmonella e sua excreção fecal em suínos em fase de crescimento infectados experimentalmente.

\section{MATERIAL E MÉTODOS}

Os animais utilizados no experimento foram selecionados entre leitões testados quanto à ausência de Salmonella nas fezes por isolamento convencional (ISO 6579) e pela Reação em Cadeia da Polimerase (CASTAGNA et al., 2005); quanto á ausência de título de IgG sérica em teste de ELISA desenvolvido com antígeno somático de $S$. Typhimurium (KICH et al., 2007). Os leitões negativos foram alojados, aos 50 dias de idade (peso médio $11,6 \mathrm{~kg}$ ), em duas salas separadas no isolamento da Embrapa Suínos e Aves. Antes do alojamento, as salas foram lavadas, desinfetadas e testadas quanto à ausência de Salmonella em suabes de piso. Um total de 24 leitões foi distribuído em dois grupos com seis leitões em cada tratamento, com duas repetições por tratamento. Os animais dos dois grupos receberam ad libitum água e ração. $\mathrm{O}$ grupo controle recebeu ração basal nutricionalmente balanceada, sem adição de antibióticos e testada quanto à ausência de Salmonella. O grupo tratado recebeu a mesma ração adicionada de probiótico em pó composto por

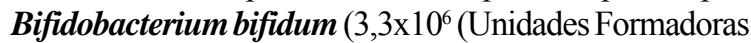

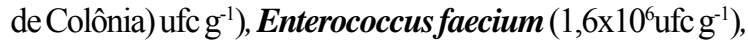
Lactobacillus acidophilus $\left(3,3 \times 10^{6} \mathrm{ufc}^{-1}\right)$, Lactobacillus plantarum $\left(1,6 \times 10^{6} \mathrm{ufc} \mathrm{g}^{-1}\right)$ e Saccharomyces cerevisiae $\left(3,3 \times 10^{5}\right.$ ufc g $\left.^{-1}\right)$ (Florafort ${ }^{\mathbb{R}}$ Vitafort, Ribeirão Preto, SP) na concentração de $1 \mathrm{~kg}$ tonelada ${ }^{-1}$ de ração. Segundo recomendação do fabricante, $5 \mathrm{~g}$ do mesmo produto em forma de pasta foi administrada individualmente no grupo tratado por via oral, nos dois primeiros dias após o alojamento.

Após duas semanas, cada animal foi inoculado pela via oral, com $10 \mathrm{~mL}$ de uma suspensão de $10^{6}$ ufc mL $\mathrm{mL}^{-1}$ de Salmonella Typhimurium DT177, sendo esse considerado o dia zero pós-inoculação (0 PI). Foram realizadas colheitas de fezes para análise microbiológica nos dias -14 e - 7 (anteriores à inoculação), e nos dias 0 , $3,7,14,21$ e 28PI. Amostras de sangue para pesquisa de IgG sérica foram coletadas nos dias -14, 0, 7, 14, 21 , 28 e 35PI. No dia 35PI (peso médio 52,1kg), os animais foram sacrificados e amostras de tonsila, pulmão, fígado, baço, linfonodos mesentérico e conteúdo cecal foram coletadas para análise microbiológica e histopatológica. Um fragmento de cinco centímetros de íleo foi coletado e fixado em solução de Bouin por 18 horas para a análise morfológica de vilosidades.

O isolamento de Salmonella a partir de fezes e vísceras foi realizado conforme descrito no protocolo da ISO 6579. A quantificação de Salmonella em amostras de fezes foi realizada pela técnica do Número mais Provável (NMP) segundo BAM (2006). Nas amostras de fezes, foram quantificadas as bactérias do gênero Lactobacillus, Enterococcus e coliformes totais conforme QUINN et al. (1998). Colônias típicas em agar Rogosa (Difco, EUA) para Lactobacillus; agar Bile Esculina (Himedia, India) para Enterococcus e agar Bile Vermelho Violeta (VRB, Himedia) para coliformes totais foram consideradas como a enumeração ( $\mathrm{ufc} \mathrm{g}^{-1}$ ) presuntiva das respectivas bactérias. As amostras de soro foram submetidas ao teste de ELISA desenvolvido por $\mathrm{KICH}$ et al. (2007). Soros que apresentaram densidades óticas (DO) $>0,169$ no teste foram considerados positivos.

As amostras de íleo foram incluídas em parafina e coradas por Hematoxilina e Eosina (HE), segundo LUNA (1968). A mensuração da altura das vilosidades foi realizada com microscópio óptico, 
utilizando objetiva $(12,5 \mathrm{X})$ com retículo e previamente calibrada. A altura da vilosidade (distância em micrômetros entre a base e o topo de vilosidades íntegras) foi medida dez vezes em três lâminas, totalizando trinta mensurações por animal.

Para a análise das variáveis NMP de Salmonella, quantificação (ufc) de bactérias nas fezes e níveis de IgG sérico, os dados foram transformados em logaritmo e analisados pelo modelo de medidas repetidas (MIXED/SAS ${ }^{\mathrm{TM}}$, 2002). As variáveis NMP de Salmonella no conteúdo cecal e medida de vilosidades do íleo foram analisadas pelo modelo de medidas únicas (GLM/SAS $\left.{ }^{\mathrm{TM}}, 2002\right)$. A presença de Salmonella em amostras de tecidos foi submetida à regressão logística (LOGISTIC/SAS ${ }^{\mathrm{TM}}$, 2002) e foram estimadas as razões de chance (odds ratio) de isolamento da bactéria.

\section{RESULTADOS E DISCUSSÃO}

Todos os grupos foram infectados por Salmonella, o que foi comprovado pelo isolamento da bactéria a partir de diferentes amostras coletadas dos animais e a ocorrência de soroconversão. Dois animais pertencentes ao grupo controle no primeiro bloco de repetição morreram antes da inoculação de $\boldsymbol{S}$. Typhimurium, com sintomas e lesões de meningite estreptocócica. Não foram observados sinais clínicos de salmonelose nos animais de ambos os grupos, quadro compatível com a infecção por $\boldsymbol{S}$. Typhimurium em suínos que resulta, predominantemente, em apresentação subclínica e estado de portador (BOYEN et al., 2008). Pneumonia intersticial foi a única lesão, compatível com a infecção por Salmonella, encontrada na análise histopatológica, e foi observada em todos os animais do grupo controle e em quatro suínos do grupo tratado com probiótico $(\mathrm{P}=0,065)$.

A soroconversão iniciou a partir do dia 7PI em ambos os grupos e houve incremento nas DOs médias até o final do experimento, sem diferença significativa entre grupos (Figura 1). Títulos de IgG sérica começam a ser detectados a partir da primeira semana pós-infecção em suínos expostos à Salmonella (KICH et al., 2007) e a frequência de animais soropositivos tem sido adotada para avaliar a presença de portadores em lotes de suínos. Essa correspondência pode ser observada no presente estudo, uma vez que todos os animais soroconverteram e foram positivos em pelo menos um dos tecidos coletados na necropsia. Entretanto, o grupo controle (Tabela 1) apresentou maior razão de chance (OR) de isolamento de Salmonella no fígado $(\mathrm{OR}=9,0, \mathrm{P}=0,01)$, linfonodos mesentéricos $(\mathrm{OR}=14,0, \mathrm{P}=0,01)$, pulmão $(\mathrm{OR}=21,0, \mathrm{P}=0,01)$ e baço $(\mathrm{OR}=9,0, \mathrm{P}=0,01)$, indicando que a administração de probiótico exerceu efeito contra a invasão da bactéria.

Ao contrário do observado nos órgãos internos, o grupo tratado com probiótico apresentou tendência à maior frequência de isolamentos em tonsilas, concordando com o relatado por SZABÒ et al. (2009). A transmissão de Salmonella ocorre, principalmente, pela via fecal-oral e resulta na colonização e invasão do epitélio intestinal, seguida da disseminação para linfonodos e órgãos internos (BOYEN et al., 2008). Porém, a importância da invasão em sítios alternativos, como as tonsilas, seguida de

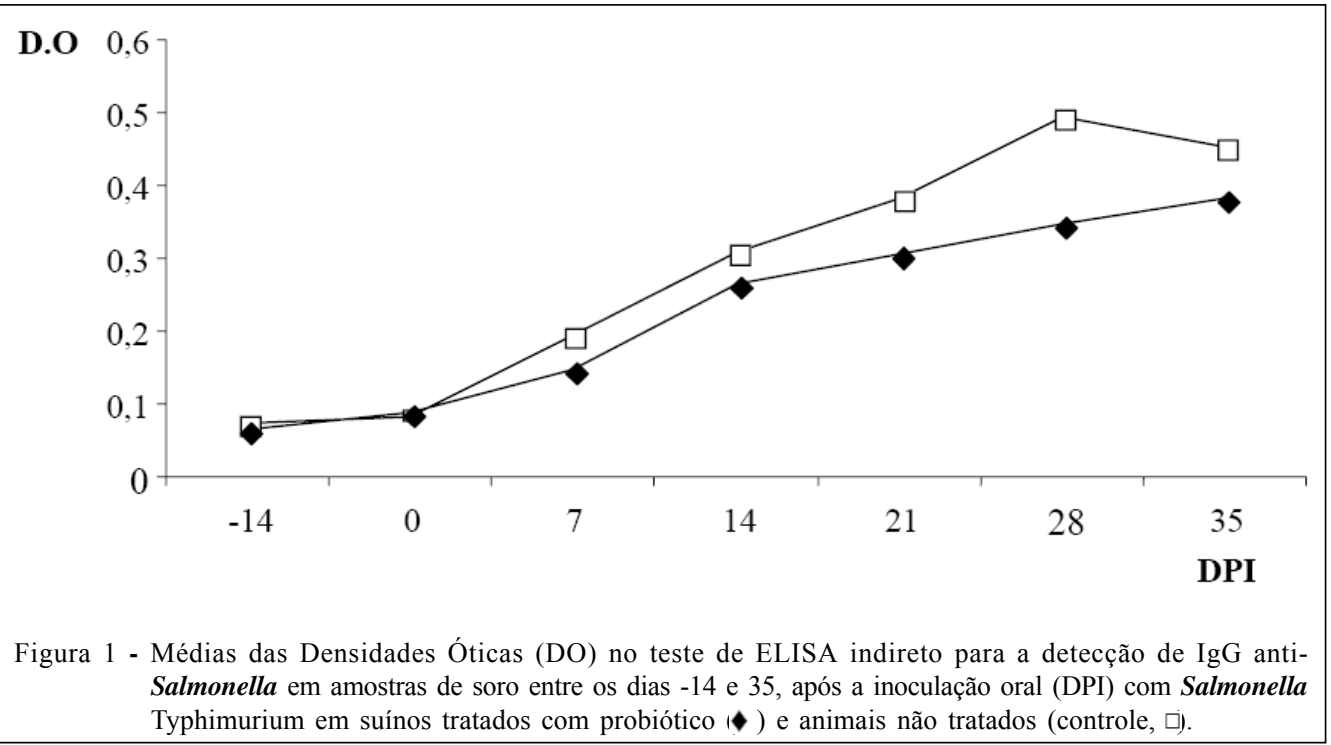

Ciência Rural, v.42, n.3, mar, 2012. 
Tabela 1 - Frequência de isolamento de Salmonella a partir de amostras coletadas na necropsia de suínos inoculados pela via oral com Salmonella Typhimurium e alimentados com ração basal (controle) e ração basal acrescida de probiótico.

\begin{tabular}{lccc}
\hline Amostra & \multicolumn{3}{c}{ Controle } \\
& $\begin{array}{c}\text { Probiótico } \\
(\mathrm{n}=10)\end{array}$ & $\mathrm{P}=12)$ & $\mathrm{P}$ \\
Baço & 6 & 3 & 0,01 \\
Conteúdo cecal & 7 & 9 & 0,89 \\
Fígado & 7 & 3 & 0,01 \\
Linfonodos mesentéricos & 8 & 4 & 0,01 \\
Pulmão & 9 & 5 & 0,01 \\
Tonsilas & 8 & 11 & 0,91 \\
\hline
\end{tabular}

colonização intestinal, já foi demonstrada experimentalmente (FEDORKA-CRAY et al., 1995; OLIVEIRA et al., 2007), indicando que medidas de controle que atuem apenas na colonização intestinal podem não ser eficazes para evitar a infecção dos animais.

Em relação ao índice de animais excretando

Salmonella nas fezes, ambos os grupos apresentaram uma elevada frequência, não sendo observada diferença significativa entre grupos (Tabela 2). $\mathrm{Na}$ quantificação de Salmonella nas fezes, houve um aumento significativo na excreção média da bactéria no grupo controle entre os dias 3PI e 7PI. O pico de excreção observado no dia 7PI pode ter sido decorrente da intensa multiplicação de Salmonella que ocorre no intestino após as etapas de colonização e invasão de enterócitos e linfonodos mesentéricos, e que leva ao aumento do número de bactérias no lúmen intestinal e nas fezes (BOYEN et al., 2008). Ao contrário, no grupo tratado com probiótico, a maior contagem fecal média de Salmonella ocorreu no dia 3PI, seguido de decréscimo significativo no dia 7PI. Esse perfil pode ter resultado da exclusão competitiva exercida pelo probiótico, ocasionando um menor grau de colonização inicial de Salmonella, seguida de excreção fecal passiva. Além disso, a menor população inicial de Salmonella colonizando o intestino pode ter influenciado, também, na quantidade de bactérias que invadiram o epitélio intestinal e alcançaram linfonodos mesentéricos e órgãos internos no grupo tratado, resultando na menor frequência de isolamentos observada nesse grupo.

Em ambos os grupos, a partir do dia 14PI, ocorreu declínio na média de Salmonella nas fezes, sem diferença entre grupos, indicando que os animais haviam entrado na fase de excreção intermitente da bactéria que caracteriza o período após a soroconversão
(BOYEN et al., 2008). No conteúdo cecal, os grupos controle e tratado com probiótico apresentaram contagem média de Salmonella entre $3,95 \log _{10} \mathrm{~g}^{-1} \mathrm{e}$ $4,35 \log _{10} \mathrm{~g}^{-1}$, respectivamente, não havendo diferença entre grupos $(\mathrm{P}=0,55)$, o que confirma que o tratamento testado não evitou a infecção dos animais nem influenciou na excreção fecal de Salmonella.

Estudos anteriores relatam efeito positivo do uso de probióticos para proteção de suínos contra a infecção por Salmonella. FEDORKA-CRAY et al. (1999) administraram cultura de bactérias cecais a leitões em fase de lactação, desafiados com $\boldsymbol{S}$. Choleraesuis, e obtiveram menor taxa de colonização intestinal no grupo tratado. CASEY et al. (2007) forneceram leite adicionado de culturas de Lactobacillus e Pediococcus a leitões desmamados e observaram menor ocorrência de diarreia e menores contagens fecais da cepa de $\boldsymbol{S}$. Typhimurium que havia sido inoculada. Por outro lado, SZABÓ et al. (2009) não obtiveram o mesmo sucesso, observando tendência de maior excreção de Salmonella em leitões tratados com uma cepa de Enterococcus faecium. Segundo CALLAWAY et al. (2008), resultados mais promissores são obtidos quando o probiótico é administrado a animais jovens, que, por estarem em fase de modificação da microbiota intestinal, são mais facilmente colonizados pelas cepas probióticas. No presente estudo, os probióticos foram testados como alternativa de controle de Salmonella em animais mais velhos, o que pode ter prejudicado o sucesso dessas bactérias em estabelecer uma colonização duradoura no intestino.

Constatou-se que não houve diferença estatística $(\mathrm{P}>0,05)$ nas contagens de bactérias cultiváveis pertencentes à microbiota intestinal avaliada, tanto entre grupos de tratamento, como entre dias de colheita de fezes após o início da administração do probiótico. As contagens para Lactobacillus variaram entre $8,36 \pm 0,18$ e 9,30 $\pm 0,14 \mathrm{ufc} \mathrm{g}^{-1}$ no grupo controle e entre $8,57 \pm 0,18$ e $9,15 \pm 0,19$ ufc g $^{-1}$ no grupo tratado. Em relação ao gênero Enterococcus, o grupo

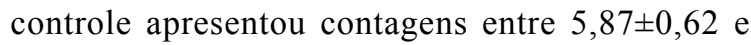
$6,79 \pm 0,3$ ufc g $^{-1}$, enquanto o grupo tratado apresentou $5,47 \pm 0,22$ até $6,99 \pm 0,27$ ufc $^{-1}$. Para coliformes totais, a contagem do grupo controle variou entre 5,57 $\pm 0,18 \mathrm{e}$ $6,58 \pm 0,26$ ufc g $^{-1}$, enquanto o grupo tratado apresentou $5,92 \pm 0,15$ e $6,75 \pm 0,14$ ufc g $^{-1}$.

Estudos anteriores relatam aumento da população de Lactobacillus presentes nas fezes de suínos desmamados, tratados com probióticos, bem como decréscimo do grupo das Enterobacteriaceae (DE ANGELIS et al., 2007). Por outro lado, a ausência de alteração dessas populações em decorrência da 
Tabela 2 - Frequência de animais positivos e médias da quantificação de Salmonella $\left(\log _{10}\right.$ ufc $\left.\mathrm{g}^{-1}\right)$ nas fezes, erros-padrão e níveis descritivos de probabilidade do teste $\mathrm{F}$ (P), entre os dias 3 e 28 pós-inoculação (DPI) oral com Salmonella Typhimurium em suínos tratados com probiótico e animais não tratados (controle).

\begin{tabular}{|c|c|c|c|c|c|}
\hline \multirow[t]{2}{*}{ DPI } & \multicolumn{2}{|c|}{ 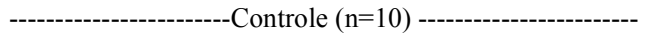 } & \multicolumn{2}{|c|}{-1n=12) - } & \multirow[t]{2}{*}{$\mathrm{P}$} \\
\hline & Animais positivos & Contagem média $\left(\log _{10} \mathrm{ufc} \mathrm{g}^{-1}\right)$ & Animais positivos & Contagem média $\left(\log _{10} \mathrm{ufc} \mathrm{g}^{-1}\right)$ & \\
\hline 3 & 6 & $1,10 \pm 0,23^{\mathrm{Aa}}$ & 8 & $5,41 \pm 1,52^{\mathrm{Ab}}$ & $<0,01$ \\
\hline 7 & 10 & $9,12 \pm 1,65^{\mathrm{Ba}}$ & 8 & $2,43 \pm 1,33^{\mathrm{Bb}}$ & 0,01 \\
\hline 14 & 7 & $2,77 \pm 0,25^{\mathrm{A}}$ & 6 & $3,76 \pm 0,17^{\text {B }}$ & 0,95 \\
\hline 21 & 5 & $1,00 \pm 0,15^{\mathrm{A}}$ & 9 & $2,34 \pm 0,20^{\mathrm{B}}$ & 0,46 \\
\hline 28 & 6 & $1,65 \pm 0,20^{\mathrm{A}}$ & 6 & $2,02 \pm 0,00^{\mathrm{B}}$ & 0,35 \\
\hline $\mathrm{P}$ & & 0,01 & & $<0,01$ & \\
\hline
\end{tabular}

a, b Médias seguidas de letras minúsculas distintas nas linhas diferem entre si pelo teste $\mathrm{t}(\mathrm{P}<0,05)$.

A, B Médias seguidas de letras maiúsculas distintas nas colunas diferem entre si pelo teste $\mathrm{t}(\mathrm{P}<0,05)$.

administração de probióticos também foi encontrada (SCHAREK et al., 2005; WALSH et al., 2008), demonstrando que os efeitos obtidos são variáveis, de acordo com o probiótico utilizado. Apesar de não ter havido efeito sobre a quantificação das bactérias investigadas no presente estudo, a modificação no perfil das espécies dos gêneros investigados, como foi relatado no estudo de SCHAREK et al. (2005), não pode ser descartada.

Alterações na microbiota entérica podem levar à modificações morfológicas nas vilosidades do intestino (BAUM et al., 2002). No presente estudo, o bloco de repetição influenciou nos resultados obtidos, que foram analisados separadamente. O tamanho médio das vilosidades $(336 \pm 10 \mu \mathrm{m})$ do grupo tratado com probiótico foi significativamente $(\mathrm{P}<0,01)$ menor do que no grupo controle $(472 \pm 10)$ no primeiro bloco. Por outro lado, no segundo bloco de repetição, o mesmo efeito não foi observado, encontrando-se uma média de $335 \pm 11 \mu \mathrm{m}$ e $325 \pm 21 \mathrm{ìm}$, respectivamente, no grupo controle e tratado. BAUM et al. (2002) relataram aumento do comprimento das vilosidades e relacionaram esse achado a modificação da microbiota intestinal causada pela administração de probióticos a suínos desmamados. Em nosso estudo, o efeito inconsistente sobre as vilosidades pode ter decorrido da baixa influência do tratamento na microbiota entérica, resultado que também foi encontrado por SCHAREK et al. (2005).

\section{CONCLUSÃO}

Os microrganismos probióticos testados no presente estudo não foram capazes de impedir a infecção ou diminuir a excreção fecal de Salmonella em suínos de crescimento infectados experimentalmente, mas diminuíram o número de portadores em linfonodos mesentéricos e órgãos internos.

\section{COMITÊ DE ÉTICA E BIOSSEGURANÇA}

O projeto está de acordo com os Princípios Éticos na Experimentação Animal aprovado pelo Comitê em Ética de Pesquisa da Universidade Federal do Rio Grande do Sul (UFRGS), sob o número 2007-962 CEP-UFRGS.

\section{REFERÊNCIAS}

BAM, Bacteriological analytical manual. Appendix 2: Most probable number determination from serial dilutions, laboratory methods. 8.ed, Ed. Rev. February, 2006. Disponível em: <http:/ /www.fda.gov/Food/scienceResearch/LaboratoryMethods/ BacteriologicalAnalyticalManualBAM/ucm 109656.htm>. Acesso em: 20 nov.2009.

BAUM, B. et al. Saccharomyces boulardi and Bacillus cereus var. Toyoi influence the morphology and the mucins of the intestine of pig. Zeitschrift Gastroenterologie, v.40, p.277284, 2002 .

BOYEN, F. et al. Non-typhoidal Salmonella infections in pigs: a closer look at epidemiology, pathogenesis and control. Veterinary Microbiology, v.130, n.1-2, p.1-19, 2008. Disponível em: <http:/ /www.sciencedirect.com.ez45.periodicos.capes.gov.br/ science?_ob=ArticleURL\&_udi=B6TD6-4RH94TW-4>. Acesso em: 11 maio, 2011. doi:10.1016/j.vetmic.2007.12.017.

CALLAWAY, T.R. et al. Probiotics, prebiotics and competitive exclusion for prophylaxis against bacterial disease. Animal Health Research Reviews, v.9, n.2, p.217-225, 2008. Disponível em: $<$ http://journals.cambridge.org.ez45.periodicos.capes.gov.br/action/ displayFulltext?type $=6 \&$ fid $=3104120 \&$ jid $=$ AHR \&volumeId $=9$ \&issueId=\&aid=3104116\&fulltext Type=RV\&fileId= S1466252308001540>. Acesso em: 11 maio, 2011. doi:10.1017/S1466252308001540.

CASEY, P.G. et al. A five-strain probiotic combination reduces pathogen shedding and alleviates disease sign in pigs challenged with Salmonella enterica serovar Typhimurium. Applied and Environmental Microbiology, v.73, n.6, p.1858-1863, 2007. Disponível em: <http://aem.asm.org/cgi/reprint/73/6/1858>. Acesso em: 11 de maio 2011. doi:10.1128/AEM.01840-06.

CASTAGNA, S.M.F. et al. Detection of Salmonella sp. from porcine origin: a comparison of a PCR method and standard 
microbiological techniques. Brazilian Journal of Microbiology, v.36, n.4, p.373-377, 2005. Disponível em: $<$ http://www.scielo.br/pdf/bjm/v36n4/v36n4a13.pdf $>$. Acesso em: 11 maio, 2011. doi: 10.1590/S1517-83822005000400013.

DE ANGELIS, M. et al. Survival and persistence of Lactobacillus plantarum 4.1 and Lactobacillus reuteri 357 in the gastrointestinal tract of pigs. Veterinary Microbiology, v.23 n.1-3, p.133-144, 2007. Disponível em: <http:// www.sciencedirect.com.ez45.periodicos.capes.gov.br/ science? ob=ArticleURL\& udi=B6TD6-4N49VK1-3>. Acesso em: 11 maio, 2011. doi: $10.1016 /$ j.vetmic. 2007.02 .022

FEDORKA-CRAY, P.J. et al. Alternate routes of invasion may affect pathogenesis of Salmonella Typhimurium in swine. Infection and Immunity, v.63, n.7, p.2658-2664, 1995. Disponível em: <http://iai.asm.org/cgi/reprint/63/7/2658>. Acesso em: 11 maio, 2011.

FEDORKA-CRAY, P.J. et al. Mucosal competitive exclusion to reduce Salmonella in swine. Journal of Food Protection v.62, n.12, p.1376-1380, 1999.

ISO. International Organization for Standardization. ISO 6579. Microbiology of food and animal feeding stuff. Annex D: Detection of Salmonella spp. in animal faeces and environmental samples from primary stage, 2007. Disponível em: <http://www.iso.org/iso/iso catalogue/>. Acesso em: 20 nov. 2009.

$\mathrm{KICH}$, J.D., et al. Development and application of an enzymelinked immunosorbent assay to detect antibodies against prevalent Salmonella serovars in swine in southern Brazil. Journal of Veterinary Diagnostic Investigation, n.19, p.510-517, 2007.

LETELLIER, A. et al. Host response to various treatments to reduce Salmonella infections in swine. Canadian Journal of Veterinary Research, v.65, p.168-172, 2001.

LUNA, L.G. Manual of the histological staining methods of the Armed Forces Institute of Pathology. New York: McGraw Hill, 1968. 258p.
OLIVEIRA, C.J., et al. Nose-to-nose transmission of Salmonella Typhimurium between weaned pigs. Veterinary Microbiology, v.125, n.3-5, p.355-361, 2007. Disponível em: <http:// www.sciencedirect.com.ez45.periodicos.capes.gov.br/ science?_ob=MImg\&_imagekey=B6TD6-4P06>. Acesso em: 11 maio, 2011. doi:10.1016/j.vetmic.2007.05.032.

QUINN, P.J. et al. Clinical veterinary microbiology. London: Mosby, 1998. 648p.

SAS Institute Inc. Systems for Microsoft Windows. Cary NC, USA, 2002-2003. (CD-ROM).

SCHAREK, L. et al. Influence of a probiotic strain on development of the immune system of sow and piglets. Veterinary Immunology and Immunopathology, v.105, n.1-2, p.151-161, 2005. Disponível em: <http:// www.sciencedirect.com.ez45.periodicos.capes.gov.br/ science?_ob=MImg\&_imagekey=B6TD5-4FD0>. Acesso em: 11 maio, 2011._doi:10.1016/j.vetimm.2004.12.022.

SCHWARZ, P. et al. Salmonella enterica: isolamento e soroprevalência em suínos abatidos no Rio Grande do Sul. Arquivo Brasileiro de Medicina Veterinária e Zootecnia. v.61, n.5, p.1028-1034, 2009. Disponível em: <http:// www.scielo.br/pdf/abmvz/v61n5/a03v61n5.pdf>. Acesso em: 11 maio, 2011. doi: 10.1590/S0102-09352009000500003.

SZABÓ, I. et al. Influence of a probiotic strain of Enterococcus faecium on Salmonella enterica serovar Typhimurium DT104 infection in a porcine animal infection model. Applied and Environmental Microbiology, v.75, n.9, p.2621-2628, 2009. Disponível em: <http://aem.asm.org/cgi/reprint/75/9/2621>. Acesso em: 11 maio, 2011. doi:10.1128/AEM.01515-08

WALSH, M.C. et al. Predominance of a bacteriocin-producing Lactobacillus salivarius component of a five-strain probiotic in the porcine ileum and effects on host immune phenotype. FEMS Microbiology Ecology, v.64, n.2, p.317-327, 2008 Disponível em: <http://onlinelibrary.wiley.com/doi/10.1111/ j.1574-6941.2008.00454.x/pdf>. Acesso em: 11 maio, 2011. doi: $10.1111 / \mathrm{j} .1574-6941.2008 .00454 . \mathrm{x}$ 